\title{
Oligotrophic Media Compared with a Tryptic Soy Agar or Broth for the Recovery of Burkholderia cepacia Complex from Different Storage Temperatures and Culture Conditions ${ }^{\mathbb{E}}$
}

\author{
Youngbeom Ahn ${ }^{1 *}$, Un Jung Lee ${ }^{2}$, Yong-Jin Lee ${ }^{3}$, John J. LiPuma ${ }^{4}$, David Hussong ${ }^{5}$, Bernard Marasa ${ }^{6}$, and \\ Carl E. Cerniglia ${ }^{1}$ \\ ${ }^{1}$ Division of Microbiology, National Center for Toxicological Research, U.S. Food and Drug Administration, Jefferson, AR 72079, USA \\ ${ }^{2}$ Division of Biochemical Toxicology, National Center for Toxicological Research, U.S. Food and Drug Administration, Jefferson, AR 72079, USA \\ ${ }^{3}$ Department of Biological Sciences, Albany State University, Albany, GA 31705, USA \\ ${ }^{4}$ Department of Pediatrics, University of Michigan, Ann Arbor, MI 48109, USA \\ ${ }^{5}$ Eagle Analytical Services, Houston, TX 77099, USA \\ ${ }^{6}$ Office of Pharmaceutical Quality, Center for Drug Evaluation and Research, U.S. Food and Drug Administration, Silver Spring, MD 20993, USA
}

Received: June 12, 2019

Revised: August 12, 2019

Accepted: August 17, 2019

First published online: August 21, 2019

${ }^{*}$ Corresponding author Phone: +1-870-543-7084 Fax: +1-870-543-7307

E-mail: young.ahn@fda.hhs.gov

S upplementary data for this paper are available on-line only at http://jmb.or.kr.

pISSN 1017-7825, eISSN 1738-8872

Copyright(C) 2019 by

The Korean Society for Microbiology and Biotechnology
The Burkholderia cepacia complex (BCC) is capable of remaining viable in low-nutrient environments and harsh conditions, posing a contamination risk in non-sterile pharmaceutical products as well as a challenge for detection. To develop optimal recovery methods to detect BCC, three oligotrophic media were evaluated and compared with nutrient media for the recovery of BCC from autoclaved distilled water or antiseptic solutions. Serial dilutions $\left(10^{-1}\right.$ to $10^{-12} \mathrm{CFU} / \mathrm{ml}$ ) of $20 \mathrm{BCC}$ strains were inoculated into autoclaved distilled water and stored at $6^{\circ} \mathrm{C}, 23^{\circ} \mathrm{C}$ and $42^{\circ} \mathrm{C}$ for 42 days. Six suspensions of Burkholderia cenocepacia were used to inoculate aqueous solutions containing $5 \mu \mathrm{g} / \mathrm{ml}$ and $50 \mu \mathrm{g} / \mathrm{ml}$ chlorhexidine gluconate (CHX) and $10 \mu \mathrm{g} / \mathrm{ml}$ benzalkonium chloride (BZK), and stored at $23^{\circ} \mathrm{C}$ for a further 199 days. Nutrient media such as Tryptic Soy Agar (TSA) or Tryptic Soy Broth (TSB), oligotrophic media $\left(1 / 10\right.$ strength TSA or TSB, Reasoner's $2^{\text {nd }}$ Agar [R2A] or Reasoner's $2^{\text {nd }}$ Broth [R2AB], and 1/3 strength $\mathrm{R} 2 \mathrm{~A}$ or $\mathrm{R} 2 \mathrm{AB}$ ) were compared by inoculating these media with $\mathrm{BCC}$ from autoclaved distilled water and from antiseptic samples. The recovery of BCC in water or antiseptics was higher in culture broth than on solid media. Oligotrophic medium showed a higher recovery efficiency than TSA or TSB for the detection of 20 BCC samples. Results from multiple comparisons allowed us to directly identify significant differences between TSA or TSB and oligotrophic media. An oligotrophic medium pre-enrichment resuscitation step is offered for the United States Pharmacopeia (USP) proposed compendial test method for BCC detection.

Keywords: Oligotrophic medium, tryptic soy agar or broth, Burkholderia cepacia complex

\section{Introduction}

The genus Burkholderia is currently comprised of 129 species [1]. Among these are 22 closely related species collectively referred to as the Burkholderia cepacia complex (BCC) [2-6]. These bacteria are opportunistic human pathogens that are commonly found in natural environments. They also have been recovered from many contaminated drug products and have become public health concerns [712]. A review of the Food and Drug Administration (FDA) pharmaceutical product recalls indicates that BCC isolates are some of the most frequently isolated microorganisms contaminating sterile and non-sterile pharmaceutical products, and several recent outbreaks of infection have been linked to antiseptics that were found to contain BCC $[11,13,14]$. Aqueous products are especially at risk because 
of the ability of BCC to remain viable in harsh conditions, including the presence of preservatives $[15,16]$.

A challenge presented by BCC species lies in their unpredictable capacity to avoid detection $[13,17]$, ability to grow in low-nutrient conditions [18], resistance to chemical preservatives [19], and the potential to cause disease especially to immunocompromised populations [13, 17]. Some strains are able to grow in distilled water at temperatures as low as $12^{\circ} \mathrm{C}$ and as high as $48^{\circ} \mathrm{C}$ [18]. Previous research has shown that some BCC strains are capable of growing in distilled water at $18^{\circ} \mathrm{C}$ or $23^{\circ} \mathrm{C}$ for up to 40 days [20] and may be able to grow in the presence of disinfectants and antimicrobial preservatives [16, 21]. The FDA is reminding drug manufacturers to use appropriate acceptance criteria (e.g., United States Pharmacopeia [USP] Chapter $<1111>$ Microbiological examination of non-sterile products: acceptance criteria for pharmaceutical preparations and substances for pharmaceutical use) [22] and test procedures (e.g., USP <61> Microbiological examination of non-sterile products: microbial enumeration tests [23] and USP <62> Microbiological examination of non-sterile products: tests for specified microorganisms [24]) to ensure that drug product components, pharmaceutical water, and finished drug products conform to appropriate quality standards. Pharmaceutical products that are contaminated with BCC may pose serious consequences to vulnerable patients (e.g., persons with compromised immune systems and persons with cystic fibrosis) and yet optimal recovery methods for BCC have not been determined. Preventing BCC contamination in drugs is an important public health goal. This can be achieved by addressing BCC detection during drug manufacturing.

Isolation and correct identification of BCC is challenging [20, 25-27]. A variety of selective and differential media have been proposed for isolating BCC [25-27], but USP methods for detection of Pseudomonas aeruginosa, including enrichment using Tryptic Soy Agar (TSA) or Tryptic Soy Broth (TSB), may not be adequate for all strains of BCC [13, $14,18]$. The recovery of microorganisms from pharmaceutical water samples may be increased by using low-nutrient media [16, 20, 28-31]. However, research is needed to compare BCC recovery using existing growth media/ methods as recommended in USP $<61>$ and USP $<62>$ with the recently developed dilute TSA (or TSB) or Reasoner's $2^{\text {nd }}$ Agar (R2A) or Reasoner's $2^{\text {nd }}$ Broth (R2AB) methods [20]. In this study, the $1 / 10 \times \mathrm{TSA} / \mathrm{B}, 1 / 3 \times \mathrm{R} 2 \mathrm{~A} / \mathrm{B}$, and $\mathrm{R} 2 \mathrm{~A} / \mathrm{B}$ is referred to as oligotrophic medium. The aim of this study was to assess the recovery of BCC using oligotrophic media as compared to the TSA or TSB at different storage temperatures in autoclaved distilled water samples as well as at different antiseptic concentrations.

\section{Materials and Methods}

\section{Bacterial Strains}

BCC isolated from either persons with cystic fibrosis or from the environment were obtained from the Burkholderia cepacia Research Laboratory and Repository at the University of Michigan [20]. Twenty BCC strains were examined after storage in autoclaved distilled water at different storage temperatures (see Table S1 to $\mathrm{S} 6$ in the supplemental material) and six strains of B. cenocepacia were examined after storage in chlorhexidine gluconate (CHX) and benzalkonium chloride (BZK) antiseptics (see Tables S7 and S8 in the supplemental material). These strains were grown on TSA or TSB at $30^{\circ} \mathrm{C}$ for 24 or $48 \mathrm{~h}$ and stored at $-80^{\circ} \mathrm{C}$ with $10 \%$ glycerol until used.

\section{Media}

The four culture media used in the comparison were TSA (or TSB), $1 / 10 \times$ TSA (i.e., $1 / 10$ strength TSA or $1 / 10 \times$ TSB), R2A (or $\mathrm{R} 2 \mathrm{AB}$ ) and $1 / 3 \times \mathrm{R} 2 \mathrm{~A}$ (or $1 / 3 \times \mathrm{R} 2 \mathrm{AB}$ ) (Table 1) [20]. TSA (or TSB) was used as a control medium. Any positive growth of BCC was further tested using B. cepacia selective agar (BCSA) with

Table 1. Formulation of enrichment media used to evaluate the B. cepacia complex culture method.

\begin{tabular}{lcccc}
\hline \multirow{2}{*}{ Component } & \multicolumn{5}{c}{ Enrichment media $(\mathrm{g} / \mathrm{l})$} \\
\cline { 2 - 5 } & TSB & $\begin{array}{c}1 / 10 \times \\
\text { TSB }\end{array}$ & $\begin{array}{c}1 / 3 \times \\
\text { R2AB }\end{array}$ & R2AB \\
\hline Pancreatic Digest of Casein & 17 & 1.7 & - & - \\
Casein Hydrolysate & - & - & 0.16 & 0.5 \\
Papaic Digest of Soybean & 3 & 0.3 & - & - \\
Casein Peptone & - & - & 0.07 & 0.25 \\
Meat Peptone & - & - & 0.07 & 0.25 \\
\hline Protein $(\mathrm{N})$ & 20 & 2 & 0.3 & 1 \\
\hline Glucose Monohydrate & 2.5 & 0.25 & - & - \\
Dextrose & - & - & 0.16 & 0.5 \\
Sodium Pyruvate & - & - & 0.1 & 0.3 \\
Soluble Starch & - & - & 0.16 & 0.5 \\
\hline Carbohydrate $(\mathrm{C})$ & 2.5 & 0.25 & 0.42 & 1.3 \\
\hline Disodium Phosphate $\left(\mathrm{Na}_{2} \mathrm{HPO}_{4}\right)$ & 2.5 & 0.25 & - & - \\
Dipotassium Phosphate $\left(\mathrm{K}_{2} \mathrm{HPO}_{4}\right)$ & - & - & 0.1 & 0.3 \\
\hline Phosphate $(\mathrm{P})$ & 2.5 & 0.25 & 0.1 & 0.3 \\
\hline Yeast Extract & - & - & 0.16 & 0.5 \\
Sodium Chloride & 5 & 0.5 & - & - \\
Magnesium Sulfate & - & - & 0.008 & 0.024 \\
\hline
\end{tabular}

TSA, R2A, and diluted agar medium $(1 / 10 \times$ TSA and $1 / 3 \times$ R2A) containing $15 \mathrm{~g}$ agar in deionized water were used. 
vancomycin, gentamicin, and polymyxin B (Thermo Fisher Scientific, USA) to confirm identity.

\section{In Autoclaved Distilled Water at Different Storage Temperatures}

Preparation of sample inocula. For the inoculation of sterile distilled water with BCC, the bacterial strains were grown on TSA at $30^{\circ} \mathrm{C}$ for $48 \mathrm{~h}$. The cultures were washed three times with autoclaved distilled water, and transferred into $20 \mathrm{ml}$ of autoclaved distilled water. The strains held in water were adjusted to an optical density corresponding to $0.38-0.4$ absorbance at a wavelength of $600 \mathrm{~nm}$ (approximate cell density $10^{14}$ colony-forming units per $\mathrm{ml}$ $(\mathrm{CFU} / \mathrm{ml}))$ in the Synergy MX spectrophotometer from BioTek Instruments, Inc. (USA). Serial dilutions of each BCC suspension were prepared in $20 \mathrm{ml}$ autoclaved distilled water to yield appropriate CFUs (serial dilutions ranging from $10^{-1}$ to $10^{-12}$ ). Each sample was prepared in triplicate and stored at $6^{\circ} \mathrm{C}$ (refrigerated incubator, ThermoFisher Scientific), at $23^{\circ} \mathrm{C}$ (at room temperature, on a lab bench) and at $42^{\circ} \mathrm{C}$ (incubator, ThermoFisher Scientific) for 42 days. In addition, uninoculated and highly inoculated $\left(>10^{14} \mathrm{CFU} / \mathrm{ml}\right)$ distilled water samples $(20 \mathrm{ml})$ were used as negative and positive controls, respectively.

Growth kinetics at different storage temperatures. To evaluate the effect of nutrient content on growth kinetics, TSB, 1/10 $\times$ TSB, $\mathrm{R} 2 \mathrm{AB}$ and $1 / 3 \times \mathrm{R} 2 \mathrm{AB}$ broth media were used. B. cenocepacia AU19236 was used for these tests and survived at $6^{\circ} \mathrm{C}$ (serial dilutions ranging from $10^{-4}$ to $10^{-6}$ ), $23^{\circ} \mathrm{C}$ (serial dilutions ranging from $10^{-8}$ to $10^{-10}$ ), and $42^{\circ} \mathrm{C}$ (serial dilutions ranging from $10^{-1}$ to $\left.10^{-3}\right)$. The $10-\mu l$ portions of the dilutions of suspensions held in water after 42 days were transferred into a 96-well plate (containing $90 \mu \mathrm{l}$ of medium per well) and incubated at $30^{\circ} \mathrm{C}$. The kinetics of growth in various broth media were monitored by the Synergy MX spectrophotometer. The kinetic software (Gen5) of the instrument was programmed to measure the absorbance at $600 \mathrm{~nm}$ every $2 \mathrm{~h}$ at $30^{\circ} \mathrm{C}$ for $48 \mathrm{~h}$ after shaking the microplates for $10 \mathrm{~s}$ at an intermediate intensity. Optical density measurements were compared for the cultures growing in TSB, $1 / 10 \times \mathrm{TSB}, \mathrm{R} 2 \mathrm{AB}$, and $1 / 3 \times$ R2AB. Estimations of the length of the lag phase (in hours; $\lambda$ ) and growth rate $(\mu)$ were determined from the mean growth curves generated. Growth curves for each temperature and strain were prepared separately by fitting data to the Baranyi model using DMFit, available at https:/ / www.combase.cc [32].

Solid media comparison at different storage temperatures. $\mathrm{BCC}$ strains were directly inoculated from distilled water cultures onto TSA (in USP <61>), $1 / 10 \times$ TSA, R2A, and $1 / 3 \times$ R2A for comparison in enumeration tests. Samples were collected on days $0,1,2,3,4,7,9,14,22,28,35$, and 42 . BCC survival was tested at $6^{\circ} \mathrm{C}$ (initial serial dilution $10^{-2}, 10^{-3}, 10^{-4}, 10^{-5}$, and $10^{-6}$ ), $23^{\circ} \mathrm{C}$ (initial serial dilution $10^{-8}, 10^{-9}$, and $10^{-10}$ ), and $42^{\circ} \mathrm{C}$ (initial serial dilution $1,10^{-1}, 10^{-2}$, and $10^{-3}$ ) for 42 days. At each time point, $10 \mu \mathrm{l}$ of serial dilutions of BCC strains were placed on various solid agar media to enumerate the bacteria [33]. The plates were incubated at $30^{\circ} \mathrm{C}$ for $48 \mathrm{~h}$ and the number of colony forming units on each plate was counted using the ProtoCOL3 automated plate counter (Synbiosis, Frederick, MD). The number of colonies was used to calculate the concentration of bacteria in each medium. Plate assays were performed in three to six replicates and the results were averaged.

Broth media comparison at different storage temperatures. Samples from distilled water cultures were used to compare the recovery efficiency of TSB (in USP $<61>$ ) , $1 / 10 \times$ TSB, R2AB, and $1 / 3 \times R 2 A B$. Ninety microliters of each broth medium were added in the same order to three sets of 96-well plates. At each time point, serial dilutions of BCC (10 $\mu$ l each) after $0,1,2,3,4,7,9,14$, $22,28,35$, and 42 days were added to each medium. BCC survived at $6^{\circ} \mathrm{C}$ (initial serial dilution $10^{-3}, 10^{-4}, 10^{-5}$, and $10^{-6}$ ), $23^{\circ} \mathrm{C}$ (initial serial dilution $10^{-12}$ ), and $42^{\circ} \mathrm{C}$ (initial serial dilution $10^{-2}, 10^{-3}, 10^{-4}$, $10^{-5}, 10^{-6}$, and $10^{-7}$ ) for 42 days were determined. Uninoculated wells were used as a baseline control. Growth of BCC strains in different growth media was determined using the Synergy MX spectrophotometer after subtracting the $\mathrm{OD}_{600}$ value of the uninoculated medium, as described previously [16, 20]. After $48 \mathrm{~h}$ incubation at $30^{\circ} \mathrm{C}$, the number of wells in which growth had occurred was recorded. Any positive growth was tested using BCSA to confirm identity. Negative broth cultures (wells with low $\left.\mathrm{OD}_{600}(0.040-0.045)\right)$ were subcultured onto BCSA to confirm a true negative result. The number of positive wells was used to calculate the concentration of bacteria in each medium. Broth assays were performed in six replicates and the results were averaged.

\section{In CHX and BZK Solutions}

Preparation of sample inocula. The diluted antiseptics (5 and $50 \mu \mathrm{g} / \mathrm{ml} \mathrm{CHX}$ and $10 \mu \mathrm{g} / \mathrm{ml}$ BZK) were prepared using autoclaved distilled water that did not include added nutrients. B. cenocepacia strains (approximately $10^{8} \mathrm{CFU} / \mathrm{ml}$ ) were incubated in water at $23^{\circ} \mathrm{C}$ for 42 days. After incubation, each $1 \mathrm{ml}$ water sample was mixed with the same volume of antiseptic solution (serial dilutions ranging from $10^{-1}$ to $10^{-6}$ ) or distilled water for control samples, so that the final chemical concentration became 5 and $50 \mu \mathrm{g} / \mathrm{ml}$ for CHX and $10 \mu \mathrm{g} / \mathrm{ml}$ for BZK, respectively, at their sub-MICs mentioned previously [16]. Each sample was prepared in triplicate and stored at $23^{\circ} \mathrm{C}$ (at room temperature, in a dark environment such as in a closed laboratory cabinet) for 199 days.

Solid media comparison in CHX and BZK. The survival rate of BCC in antiseptics was evaluated after 199 days by introducing $B$. cenocepacia to $5 \mu \mathrm{g} / \mathrm{ml} \mathrm{CHX} \mathrm{(initial} \mathrm{serial} \mathrm{dilution} 1,10^{-1}$, and $10^{-2}$ ), $50 \mu \mathrm{g} / \mathrm{ml} \mathrm{CHX} \mathrm{(initial} \mathrm{serial} \mathrm{dilution} 1$ and $10^{-1}$ ), and $10 \mu \mathrm{g} / \mathrm{ml}$ BZK (initial serial dilution 1 and $10^{-1}$ ) [16, 21]. Ten $\mu$ l serial dilutions of antiseptics with BCC strains were placed on TSA, $1 / 10 \times$ TSA, $1 / 3 \times \mathrm{R} 2 \mathrm{~A}$ and $\mathrm{R} 2 \mathrm{~A}$ to recover the bacteria and incubated at $30^{\circ} \mathrm{C}$ for $48 \mathrm{~h}$. All counts were performed as described above.

Broth media comparison in CHX and BZK. Broth media were prepared as described in previous broth medium comparisons $[16,20]$. After 199 days, serial dilutions of BCC (10 $\mu \mathrm{l}$ each) were added to each broth medium to achieve cell densities of $10^{5}, 10^{4}$, 
and $10^{3} \mathrm{CFU} / \mathrm{ml}$. B. cenocepacia survived at 5 and $50 \mu \mathrm{g} / \mathrm{ml}$ for $\mathrm{CHX}$ and $10 \mu \mathrm{g} / \mathrm{ml} \mathrm{BZK} \mathrm{CFU} / \mathrm{ml}$ (from initial serial dilution $10^{-1}$, $10^{-2}$, and $10^{-3}$ ) were determined as described above.

\section{Statistical Analysis}

The number of colony forming units for BCC was statistically evaluated by the Mann-Whitney Rank Sum Test using SigmaPlot software (GraphPad Software, Inc. USA). The number of positive broth media for BCC was statistically evaluated by the $\chi^{2}$-test using Social Science Statistics web-based software (https:// www.socscistatistics.com/Default.aspx).

The SAS statistical package (version 9.4; SAS Institute Inc.) and $R$ language (version 3.2.3) were used for analyzing data from solid and broth media. All statistical tests were two-tailed, with a significance level of 0.05 . For data analysis of solid media, raw data were transformed to stabilize the data variance from the number of observed bacteria to the proportion of observed bacteria. Descriptive statistics, including means with standard deviations

A

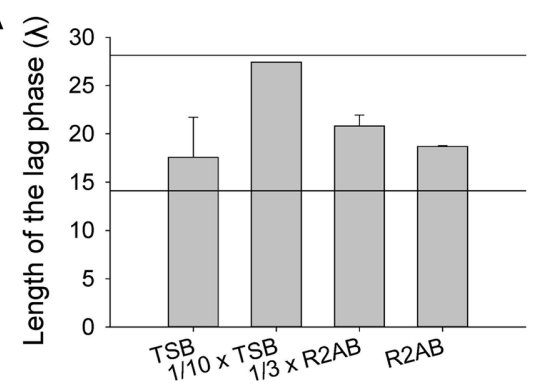

B

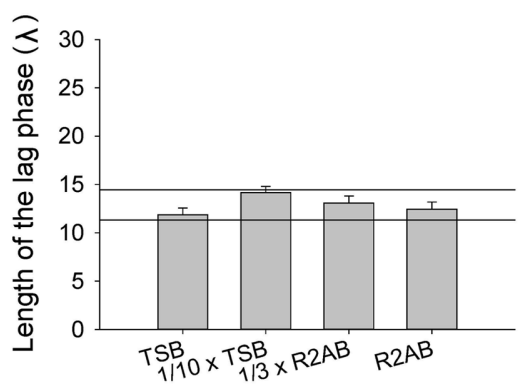

C

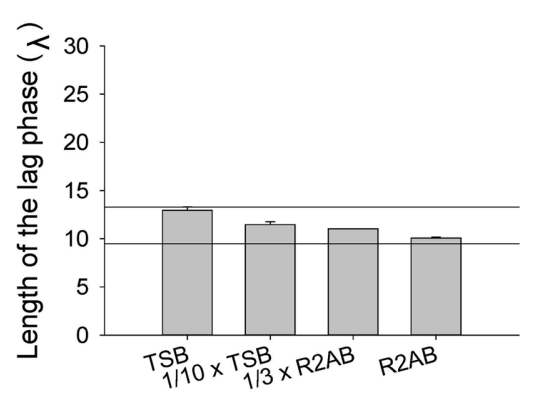

(SDs), were reported for each culture media. Normalization of raw data was calculated by the equation shown below.

$$
\text { Normalization }=\frac{\text { number of bacteria } a_{\text {it }}}{\max \left(\text { number of bacteria } a_{t}\right)} .
$$

where $i$ represents the number of bacteria of different culture media $(i=1,2,3,4)$, and $t$ represents the number of bacteria of different culture media at trial $(t=1,2, \ldots 368)$.

Differences between media groups were analyzed using the one-way analysis of variance (ANOVA) followed by Tukey's HSD test. Univariate analyses were performed using ANOVA for continuous variables and Pearson's $\chi^{2}$-test for categorical variables to explore significant differences among groups. A Tukey's honest significant difference (HSD) test on ANOVA was applied to examine pairwise differences between groups for continuous variables.

For data analysis from broth media, a macro, CHISQ_MC, was implemented to perform a Tukey-type multiple comparison on
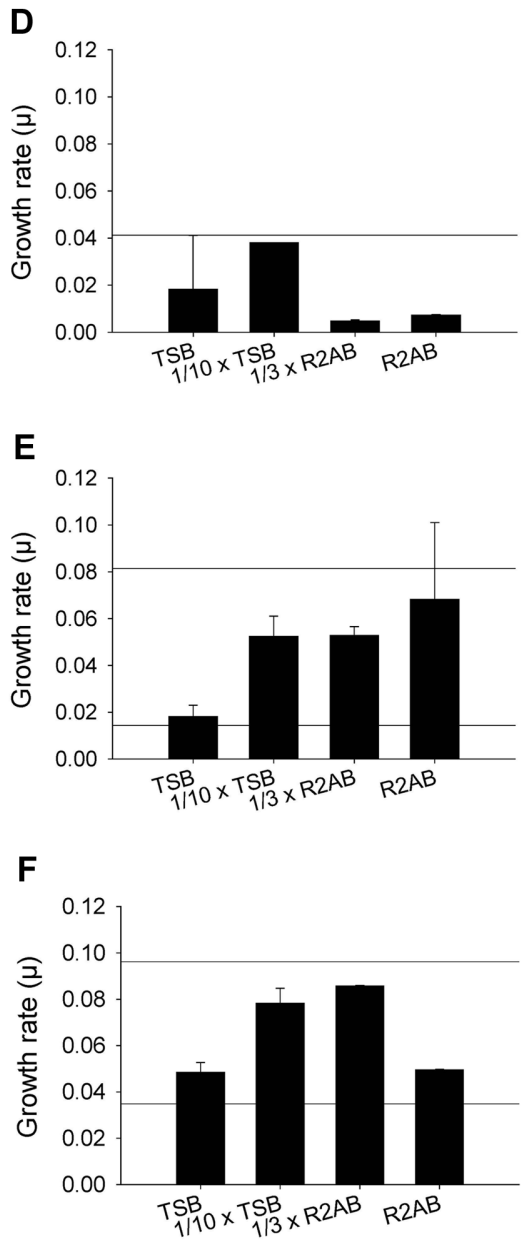

Fig. 1. The lag phase $(\lambda ; \mathbf{A}, \mathbf{B}$, and $\mathbf{C})$ and growth rate $(\mu ; \mathbf{D}, \mathbf{E}$, and $\mathbf{F})$ of B. cenocepacia AU19236 inoculated in TSB, $1 / 10 \times$ TSB, $1 / 3 \times$ $\mathrm{R} 2 \mathrm{AB}$ and $\mathrm{R} 2 \mathrm{AB}$ medium stored at $6{ }^{\circ} \mathrm{C}(\mathrm{A}$ and $\mathrm{D}), 25^{\circ} \mathrm{C}(\mathrm{B}$ and $\mathrm{E})$ and $42^{\circ} \mathrm{C}(\mathrm{C}$ and $\mathrm{F})$ for 42 days using the Baranyi growth model. Solid lines show the $95 \%$ upper and lower predicted interval. 
Pearson's $\chi^{2}$-test for categorical variables [34]. The calculated $\chi^{2}$-test statistics and $p$-values are for all pairs of groups.

\section{Results}

Compare the Oligotrophic Media to the Current USP $<61>$ Media in Autoclaved Distilled Water

Growth kinetics in TSB and R2AB at different storage temperatures. To understand the effects of temperature on survival, the $20 \mathrm{BCC}$ strains were stored at three temperatures $\left(6^{\circ} \mathrm{C}, 23^{\circ} \mathrm{C}\right.$, and $\left.42^{\circ} \mathrm{C}\right)$ for 42 days and recovered in various media. In general, survival was observed at $6^{\circ} \mathrm{C}, 23^{\circ} \mathrm{C}$, and $42^{\circ} \mathrm{C}$, and no species-specific trend was noted. Growth of B. cenocepacia AU19236 was observed when media were inoculated with initial concentrations between $10^{2}$ and $10^{\circ} \mathrm{CFU} / \mathrm{ml}$ in distilled water stored at $6^{\circ} \mathrm{C}$ and $23^{\circ} \mathrm{C}$, and between $10^{8}$ and $10^{6} \mathrm{CFU} / \mathrm{ml}$ in distilled water stored at $42^{\circ} \mathrm{C}$ for 42 days. Growth was observed in TSB, $1 / 10 \times$ TSB, $\mathrm{R} 2 \mathrm{AB}$ and $1 / 3 \times \mathrm{R} 2 \mathrm{AB}$ broth media after incubation for $24 \mathrm{~h}$ at $30^{\circ} \mathrm{C}$ for B. cenocepacia AU19236 and kinetics were described using the Baranyi model [32]. The average $R^{2}$ values for growth curves of B. cenocepacia AU19236 inoculated on TSB, $1 / 10 \times \mathrm{TSB}, \mathrm{R} 2 \mathrm{AB}$ and $1 / 3 \times \mathrm{R} 2 \mathrm{AB}$ and fitted to the Baranyi model, were $>0.98$. The high $\mathrm{R}^{2}$ values were obtained in average growth curves because the regression line approximated the observed data points. Cultures in distilled water stored at $6^{\circ} \mathrm{C}$ showed a much longer lag time $(\lambda)$, ranging between 17.6 and $27.4 \mathrm{~h}$ (Fig. 1A). No significant differences were observed between the lag times estimated for different media at $23^{\circ} \mathrm{C}$ and $42^{\circ} \mathrm{C}(10.1$ and $14.2 \mathrm{~h}$, respectively) (Figs. $1 \mathrm{~B}$ and $1 \mathrm{C}$ ). The lag time values $(\lambda)$ were greater in $1 / 10 \times$ TSB, R2AB and $1 / 3 \times$ $\mathrm{R} 2 \mathrm{AB}$ than in $\mathrm{TSB}$ at $6^{\circ} \mathrm{C}$ and $23^{\circ} \mathrm{C}$, but not at $42^{\circ} \mathrm{C}$. However, lag time fell within the $95 \%$ confidence interval, irrespective of the media used $(p>0.05)$, although the lag time was a bit longer for $1 / 10 \times$ TSB. Furthermore, growth rate $(\mu)$ did not significantly differ regardless of the media used $(p>0.05)$, although the growth rate was greater for more favorable growth media, such as $1 / 10 \times \mathrm{TSB}, \mathrm{R} 2 \mathrm{AB}$ and $1 / 3 \times \mathrm{R} 2 \mathrm{AB}$, compared to TSB at $23^{\circ} \mathrm{C}$ and $42^{\circ} \mathrm{C}$, but not at $6^{\circ} \mathrm{C}$ (Figs. 1D-1F)

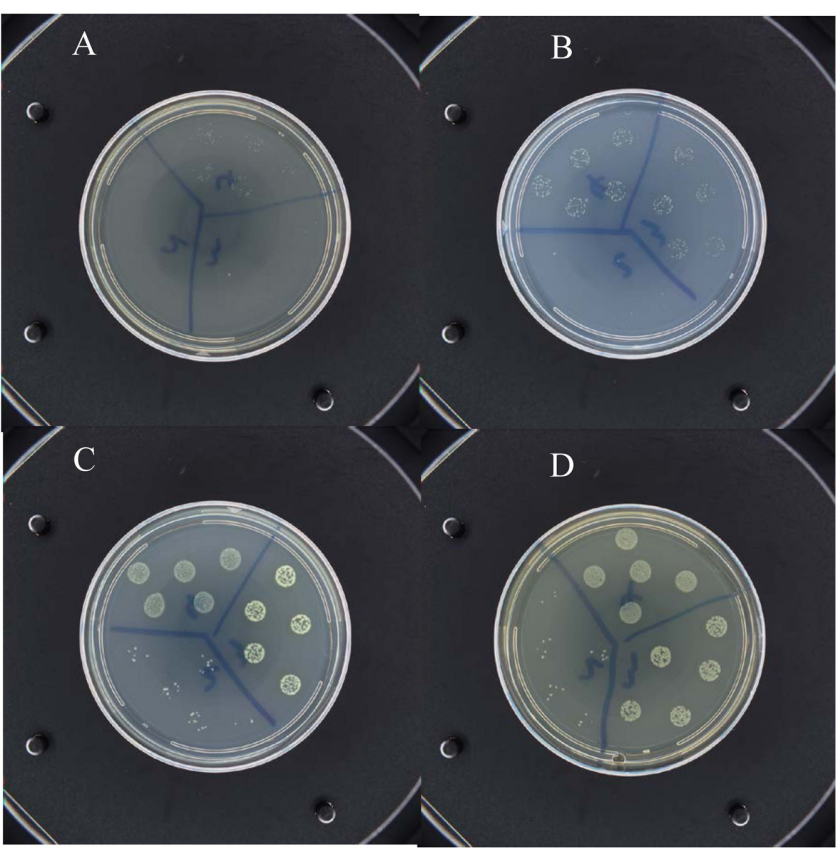

Fig. 2. Plate images of B. cenocepacia AU19236 grown on TSA (A), $1 / 10 \times$ TSA (B), $1 / 3 \times$ R2A (C), and R2A (D) media stored at $42^{\circ} \mathrm{C}$ for 42 days.

For comparison with TSA, a series of three dilutions was plated (five times) for 20 strains, and imaged using the ProtoCOL3 automated plate counter.

TSA and oligotrophic solid media comparison at different storage temperatures. For evaluation of viable colony counts in solid media, each plate was counted using the ProtoCOL3 automated plate counter (Fig. 2). After 42 days of incubation, all of the agars allowed recovery of bacteria fairly easily due to the high number of colonies that were present in the distilled water at $6^{\circ} \mathrm{C}\left(10^{4}-10^{8} \mathrm{CFU} / \mathrm{ml}\right)$ (see Table S1), and $23^{\circ} \mathrm{C}\left(10^{7}-10^{12} \mathrm{CFU} / \mathrm{ml}\right)$ (see Table S2) (Table 2). However, when 20 BCC strains were plated on solid medium, only eight (B. arboris AU22095, B. lata HI4002 256 B. cenocepacia AU1054, B. cenocepacia AU0222, B. cenocepacia AU19236, B. cenocepacia HI2976, B. cenocepacia HI2485 and B. cenocepacia J2315) grew after 42 days at $42^{\circ} \mathrm{C}\left(10^{2}-10^{6}\right.$ $\mathrm{CFU} / \mathrm{ml}$ ) in distilled water (see Table S3). The remaining

Table 2. Colony counts of B. cepacia complex at $1-10^{-10}$ dilutions in nonselective solid media at $6^{\circ} \mathrm{C}, 23^{\circ} \mathrm{C}$, and $42^{\circ} \mathrm{C}$ for 42 days.

\begin{tabular}{ccccccc}
\hline $\begin{array}{c}\text { Temperature } \\
\left({ }^{\circ} \mathrm{C}\right)\end{array}$ & Tested initial serial dilution & $\begin{array}{c}\text { Number of recovery } \\
(\mathrm{CFU} / \mathrm{ml})\end{array}$ & TSA & $1 / 10 \times$ TSA & $1 / 3 \times \mathrm{R} 2 \mathrm{~A}$ & $\mathrm{R} 2 \mathrm{~A}$ \\
\hline 6 & $10^{-6}, 10^{-5}, 10^{-4}, 10^{-3}, 10^{-2}$ & $10^{8}$ & $1.67 \pm 6.41$ & $1.49 \pm 5.93$ & $1.79 \pm 6.81$ & $1.95 \pm 7.31$ \\
23 & $10^{-10}, 10^{-9}, 10^{-8}$ & $10^{12}$ & $3.44 \pm 5.09$ & $4.18 \pm 6.17$ & $4.17 \pm 5.62$ & $4.46 \pm 5.78^{*}$ \\
42 & $10^{-3}, 10^{-2}, 10^{-1}, 1$ & $10^{5}$ & $0.57 \pm 1.39$ & $2.01 \pm 4.17^{*}$ & $6.56 \pm 15.05^{*}$ & $6.53 \pm 14.72^{*}$ \\
\hline
\end{tabular}

*There is a statistically significant difference between TSA and other medium groups $(p<0.05)$. 
strains did not grow on solid medium after nine days at $42^{\circ} \mathrm{C}$ despite longer incubation times of up to $96 \mathrm{~h}$.

Under $6^{\circ} \mathrm{C}$ storage conditions after 42 days, all of the agars allowed recovery of approximately $10^{4}-10^{8} \mathrm{CFU} / \mathrm{ml}$ (Table 2, see Table S1). B. lata HI4002, B. cenocepacia HI2976 and $B$. cenocepacia HI2485 were among the BCC which exhibited a high colony count of $10^{8} \mathrm{CFU} / \mathrm{ml}$. The colony counts were slightly higher and more variable on $1 / 3 \times$ $\mathrm{R} 2 \mathrm{~A}\left(1.79 \pm 6.81 \times 10^{8} \mathrm{CFU} / \mathrm{ml}\right)$ and R2A $\left(1.95 \pm 7.31 \times 10^{8}\right.$ $\mathrm{CFU} / \mathrm{ml})$ than in TSA $\left(1.67 \pm 6.41 \times 10^{8} \mathrm{CFU} / \mathrm{ml}\right)$. The Mann-Whitney Rank Sum Test was performed to compare the difference between TSA and 1/10 $\times$ TSA, 1/3 $\times$ R2A, and $\mathrm{R} 2 \mathrm{~A}$, and a significant difference was not found $(p<$ $0.05)$. In distilled water at $23^{\circ} \mathrm{C}$, an initial population of $10^{12} \mathrm{CFU} / \mathrm{ml}$ of $\mathrm{BCC}$ remained unchanged on various media. The colony counts were higher and more variable in $1 / 10 \times \operatorname{TSA}\left(4.18 \pm 6.17 \times 10^{12} \mathrm{CFU} / \mathrm{ml}\right), 1 / 3 \times \mathrm{R} 2 \mathrm{~A}(4.17 \pm$ $\left.5.62 \times 10^{12} \mathrm{CFU} / \mathrm{ml}\right)$ and R2A $\left(4.46 \pm 5.78 \times 10^{12} \mathrm{CFU} / \mathrm{ml}\right)$ than in TSA $\left(3.44 \pm 5.09 \times 10^{12} \mathrm{CFU} / \mathrm{ml}\right)$ (Table 2, see Table S2). The Mann-Whitney Rank Sum Test was performed to compare the difference between TSA and R2A, and a significant difference was found $(p<0.041)$. At $42^{\circ} \mathrm{C}$, only eight strains grew to approximately $10^{5} \mathrm{CFU} / \mathrm{ml}$ (Table 2, see Table S3). The colony counts were higher and more variable in $1 / 10 \times$ TSA $\left(2.01 \pm 4.17 \times 10^{5} \mathrm{CFU} / \mathrm{ml}\right), 1 / 3 \times$ $\mathrm{R} 2 \mathrm{~A}\left(6.56 \pm 15.05 \times 10^{5} \mathrm{CFU} / \mathrm{ml}\right)$ and R2A $(6.53 \pm 14.72 \times$ $\left.10^{5} \mathrm{CFU} / \mathrm{ml}\right)$ than in TSA $\left(0.57 \pm 1.39 \times 10^{5} \mathrm{CFU} / \mathrm{ml}\right)$. The Mann-Whitney Rank Sum Test was performed to compare the difference and showed significant differences between TSA and oligotrophic media, such as $1 / 10 \times$ TSA $(p=0.008)$, $1 / 3 \times \mathrm{R} 2 \mathrm{~A}(p<0.001)$, and R2A $(p<0.001)$.

TSB and oligotrophic broth media comparison at different storage temperatures. The TSB, $1 / 10 \times \mathrm{TSB}, 1 / 3 \times \mathrm{R} 2 \mathrm{AB}$, and $\mathrm{R} 2 \mathrm{AB}$ broth media were evaluated for their ability to recover $\mathrm{BCC}$ at $6^{\circ} \mathrm{C}, 23^{\circ} \mathrm{C}$, and $42^{\circ} \mathrm{C}$ (Table 3). At $6^{\circ} \mathrm{C}$ storage, compared with $1 / 10 \times \mathrm{TSB}, 1 / 3 \times \mathrm{R} 2 \mathrm{AB}$, and $R 2 A B$, recovery was less efficient in TSB media, with the portion of recovery wells of $351 / 480$ (number of recovery/ number of tests), 345/480, and 353/480, respectively (Table 3, see Table S4). The $\chi^{2}$ test on absolute numbers tested for significant differences in the frequency of growth between broth media. Significance was set at $p<0.05$. The statistical analysis of data reveals that there was significant difference between TSB and $1 / 10 \times \operatorname{TSB}\left(\chi^{2}\right.$ statistic $=$ 9.3528, $p=0.0022), 1 / 3 \times \mathrm{R} 2 \mathrm{AB}\left(\chi^{2}\right.$ statistic $\left.=6.093, p=0.0086\right)$, $\mathrm{R} 2 \mathrm{AB}\left(\chi^{2}\right.$ statistic $\left.=10.2594, p=0.00136\right)$ at $6^{\circ} \mathrm{C}$ for 42 days storage. Evaluation of the four broths inoculated with the lowest colony numbers $\left(10^{-12}\right)$ indicated that $1 / 10 \times \mathrm{TSB}, 1 / 3$ $\times R 2 A B$, and $R 2 A B$ supported the most efficient recovery of $\mathrm{BCC}$ from $23^{\circ} \mathrm{C}$ distilled water for 42 days. Differences in recovery of $\mathrm{BCC}$ among the TSB, $1 / 10 \times \mathrm{TSB}, 1 / 3 \times \mathrm{R} 2 \mathrm{AB}$, and R2AB media occurred in $39,94,107,79$ of the 480 experimental trials, respectively (Table 3, see Table S5). Statistical analyses showed that TSB was less effective than $1 / 10 \times$ TSB $\left(\chi^{2}\right.$ statistic $\left.=26.4022, p<0.05\right), 1 / 3 \times \mathrm{R} 2 \mathrm{AB}$ $\left(\chi^{2}\right.$ statistic $\left.=37.3518, p<0.05\right)$, and $\mathrm{R} 2 \mathrm{AB}\left(\chi^{2}\right.$ statistic $=$ $15.4596, p<0.05)$ media $(p<0.05)$. The recovery of BCC after 42 days of storage at $42^{\circ} \mathrm{C}$ is shown in Table 3 and Table S6 in the supplemental material. The $\chi^{2}$ statistic test was performed to compare the difference between TSA and $1 / 10 \times \mathrm{TSB}, 1 / 3 \times \mathrm{R} 2 \mathrm{AB}$, and R2AB media, and no significant difference was found $(p>0.05)$ (Table 3 , see Table S6).

\section{Recovery of B. cenocepacia from CHX and BZK}

TSA and dilute solid media comparison at different concentration of antiseptics. Water-adapted 6 B. cenocepacia strains were suspended in 5 and $50 \mu \mathrm{g} / \mathrm{ml}$ of CHX or $10 \mu \mathrm{g} / \mathrm{ml}$ of BZK. In 5 and $50 \mu \mathrm{g} / \mathrm{ml}$ of CHX solutions, colony counts were slightly higher in $1 / 10 \times$ TSA $(7.06 \pm$ $6.5 \times 10^{4} \mathrm{CFU} / \mathrm{ml}, 3.73 \pm 3.93 \times 10^{3} \mathrm{CFU} / \mathrm{ml}$ ) than in TSA $\left(6.59 \pm 5.12 \times 10^{4} \mathrm{CFU} / \mathrm{ml}, 3.03 \pm 3.42 \times 10^{3} \mathrm{CFU} / \mathrm{ml}\right)$, respectively (Table 4, see Table S7). The Mann-Whitney Rank Sum Test was performed to compare the difference between TSA and 1/10 $\times$ TSA, and a significant difference

Table 3. Number of positive wells (number of wells set up) of B. cepacia complex at $10^{-2}-10^{-12}$ dilutions in nonselective broth media at $6^{\circ} \mathrm{C}, 23^{\circ} \mathrm{C}$, and $42^{\circ} \mathrm{C}$ for 42 days.

\begin{tabular}{|c|c|c|c|c|c|}
\hline Temperature $\left({ }^{\circ} \mathrm{C}\right)$ & Tested initial serial dilution & TSB & $1 / 10 \times \mathrm{TSB}$ & $1 / 3 \times \mathrm{R} 2 \mathrm{AB}$ & $\mathrm{R} 2 \mathrm{AB}$ \\
\hline 6 & $10^{-6}, 10^{-5}, 10^{-4}, 10^{-3}$ & $307 / 480^{a}$ & $351 / 480^{b}$ & $345 / 480^{b}$ & $353 / 480^{b}$ \\
\hline 23 & $10^{-12}$ & $39 / 480$ & $94 / 480^{\mathrm{b}}$ & $107 / 480^{\mathrm{b}}$ & $79 / 480^{\mathrm{b}}$ \\
\hline 42 & $10^{-7}, 10^{-6}, 10^{-5}, 10^{-4}, 10^{-3}, 10^{-2}$ & $246 / 288$ & $241 / 288$ & $241 / 288$ & $244 / 288$ \\
\hline
\end{tabular}

${ }^{\mathrm{a}}$ Number of recovery/number of tests.

${ }^{\mathrm{b}}$ There is a statistically significant difference between TSA and other medium groups $(p<0.05)$. 
Table 4. Colony counts of 6 B. cenocepacia strains at $1-10^{-2}$ dilutions in nonselective solid media at $23^{\circ} \mathrm{C}$ for 199 days

\begin{tabular}{ccccccc}
\hline $\begin{array}{c}\text { Antiseptics } \\
\text { (concentration) }\end{array}$ & Tested initial serial dilution & $\begin{array}{c}\text { Number of recovery } \\
(\text { CFU } / \mathrm{ml})\end{array}$ & TSA & $1 / 10 \times$ TSA & $1 / 3 \times$ R2A & R2A \\
\hline CHX $(5 \mu \mathrm{g} / \mathrm{ml})$ & $10^{-2}, 10^{-1}, 1$ & $10^{4}$ & $6.59 \pm 5.12$ & $7.06 \pm 6.5$ & $6.36 \pm 5.96$ & $6.67 \pm 6.54$ \\
$\mathrm{CHX}(50 \mu \mathrm{g} / \mathrm{ml})$ & $10^{-1}, 1$ & $10^{3}$ & $3.03 \pm 3.42$ & $3.73 \pm 3.93$ & $2.88 \pm 3.00$ & $3.03 \pm 3.42$ \\
$\mathrm{BZK}(10 \mu \mathrm{g} / \mathrm{ml})$ & $10^{-1}, 1$ & $10^{3}$ & $1.27 \pm 1.28$ & $1.51 \pm 1.77$ & $1.58 \pm 1.73$ & $1.79 \pm 2.24$ \\
\hline
\end{tabular}

Table 5. Number of positive wells (number of wells set up) of B. cenocepacia at $10^{-1}-10^{-3}$ dilutions in nonselective broth media at $23^{\circ} \mathrm{C}$ for 199 days.

\begin{tabular}{cccccc}
\hline Antiseptics (concentration) & Tested initial serial dilution & TSB & $1 / 10 \times$ TSB & $1 / 3 \times$ R2AB & R2AB \\
\hline CHX $(5 \mu \mathrm{g} / \mathrm{ml})$ & $10^{-3}, 10^{-2}, 10^{-1}$ & $116 / 144^{\mathrm{a}}$ & $107 / 144$ & $116 / 144$ & $134 / 144^{\mathrm{b}}$ \\
CHX $(50 \mu \mathrm{g} / \mathrm{ml})$ & $10^{-3}, 10^{-2}, 10^{-1}$ & $94 / 144$ & $78 / 144$ & $85 / 144$ & $114 / 144^{\mathrm{b}}$ \\
BZK $(10 \mu \mathrm{g} / \mathrm{ml})$ & $10^{-3}, 10^{-2}, 10^{-1}$ & $67 / 144$ & $62 / 144$ & $95 / 144^{\mathrm{b}}$ & $113 / 144^{\mathrm{b}}$ \\
\hline
\end{tabular}

${ }^{a}$ Number of recovery/number of tests.

${ }^{\mathrm{b}}$ There is a statistically significant difference between TSA and other medium groups $(p<0.05)$.

was not found $(p<0.05)$. Also, in $10 \mu \mathrm{g} / \mathrm{ml}$ BZK solutions, the population counts were slightly higher in $1 / 10 \times$ TSA $\left(1.51 \pm 1.77 \times 10^{3} \mathrm{CFU} / \mathrm{ml}\right), 1 / 3 \times \mathrm{R} 2 \mathrm{~A}\left(1.58 \pm 1.73 \times 10^{3}\right.$ $\mathrm{CFU} / \mathrm{ml}), \mathrm{R} 2 \mathrm{~A}\left(1.79 \pm 2.24 \times 10^{3} \mathrm{CFU} / \mathrm{ml}\right)$ than in TSA $\left(1.27 \pm 1.28 \times 10^{3} \mathrm{CFU} / \mathrm{ml}\right)$, respectively. There was no difference in recovery by Mann-Whitney Rank Sum Test.

TSB and oligotrophic broth media comparison at different concentration of antiseptics. The TSB, $1 / 10 \times \mathrm{TSB}, 1 / 3 \times$ $\mathrm{R} 2 \mathrm{AB}$, and $\mathrm{R} 2 \mathrm{AB}$ broth media were evaluated for their ability to recover B. cenocepacia in 5 and $50 \mu \mathrm{g} / \mathrm{ml}$ of $\mathrm{CHX}$ or $10 \mu \mathrm{g} / \mathrm{ml}$ of BZK. Recovery was more efficient in $\mathrm{R} 2 \mathrm{AB}$ media, with the portion of recovery wells of 134/144 (number of recovery/number of tests, from $5 \mu \mathrm{g} / \mathrm{ml}$ of CHX), 114/144 (50 $\mu \mathrm{g} / \mathrm{ml}$ of CHX), and 113/144 $(10 \mu \mathrm{g} / \mathrm{ml}$ of BZK), respectively (Table 5 , see Table S8). The statistical analysis of data reveals that there was significant difference between TSB and R2AB of $5 \mu \mathrm{g} / \mathrm{ml}$ of $\mathrm{CHX}\left(\chi^{2}\right.$ statistic $=$ 6.9231, $p=0.0085), 50 \mu \mathrm{g} / \mathrm{ml}$ of $\mathrm{CHX}\left(\chi^{2}\right.$ statistic $=9.8223, p=$ $0.0017)$, and $10 \mu \mathrm{g} / \mathrm{ml}$ of BZK $\left(\chi^{2}\right.$ statistic $\left.=31.3481, p<0.05\right)$.

\section{Comparison by Statistical Analysis}

TSA and oligotrophic solid media pairwise comparison. A Tukey's HSD test on ANOVA was performed to examine pairwise differences of the proportion of the colony counts between different agar media. R2A had the highest mean of $\mathrm{BCC}$ recovery $(0.84$, standard deviation $=0.20)$, which was similar to the growth rate of $1 / 3 \times \mathrm{R} 2 \mathrm{~A}(0.82$, standard deviation $=0.22$ ) (Table 6A). Both recovery of BCC in R2A and $1 / 3 \times \mathrm{R} 2 \mathrm{~A}$ media were significantly different from recovery of BCC in TSA media $(p<0.05) .1 / 10 \times$ TSA was more likely to have recovery $(0.69$, standard deviation $=$ $0.28)$ compared with TSA $(0.61$, standard deviation $=0.30)$ $(p<0.05)$.

TSB and oligotrophic broth media pairwise comparison. A Tukey-type multiple comparison on Pearson's $\chi^{2}$-test was performed to evaluate pairwise difference of the recovered BCC between different broth media. After adjusting for multiple comparisons, the recovery ability of BCC in TSB media was significantly different from $1 / 3 \times$

Table 6. Summary of descriptive statistics and results of post hoc tests using Tukey's HSD test on ANOVA (A) and Tukey-type multiple comparison on Pearson's $\chi^{2}$ test (B).

(A) Solid media

\begin{tabular}{ccccc}
\hline & TSA & $1 / 10 \times$ TSA & $1 / 3 \times$ R2A & R2A \\
\hline Mean of rate (standard deviation) & $0.61(0.30)$ & $0.69(0.28)^{*}$ & $0.82(0.22)^{*}$ & $0.84(0.20)^{*}$ \\
\hline${ }^{*} p<0.05$ significantly different from TSA. & & &
\end{tabular}

(B) Broth media

\begin{tabular}{cccc}
\hline & TSB & $1 / 10 \times$ TSB & $1 / 3 \times$ R2AB \\
\hline Number of positives/number of negatives & $1383 / 873$ & $1477 / 809$ & $1506 / 750^{*}$ \\
\hline$* 0.05$ significantly different from TSA. & & $1557 / 669^{*}$
\end{tabular}


R2AB and R2AB, separately. The TSB media was observed to have lower counts of BCC compared with $1 / 10 \times$ TSB, but this finding did not reach statistical significance (Table 6B).

\section{Discussion}

Species in the BCC are able to remain viable under harsh conditions such as in water, organic solvents, antiseptics, and liquids with low nutrient levels for prolonged periods $[13,15,16,18,35-39]$. The survival of BCC at temperatures ranging from $10^{\circ} \mathrm{C}$ to $50^{\circ} \mathrm{C}$ has been previously reported [18]. Burkholderia pseudomallei (not a species in the BCC) remained viable when incubated at $8^{\circ} \mathrm{C}$ for more than 1133 days, and at above $40^{\circ} \mathrm{C}$ for less than one month [40]. Also, B. pseudomallei survived in distilled water for 200 days or 16 years $[36,38]$. Previously, we reported that $B$. cenocepacia can persist in distilled water at $18^{\circ} \mathrm{C}$, and $23^{\circ} \mathrm{C}$ for 40 days [20]. In this investigation, the survival of $20 \mathrm{BCC}$ strains in distilled water samples was observed at $6^{\circ} \mathrm{C}$ and $23^{\circ} \mathrm{C}$ over a 42-day period, which slightly surpasses the previously examined 40-day period (see Table S1 to S6). However, 12 BCC strains did not grow when incubated at $42^{\circ} \mathrm{C}$ during the same time period. Although, we observed that six B. cenocepacia strains endured nutrient-depleted environments in a wide range of temperatures $\left(6^{\circ} \mathrm{C}\right.$ to $\left.42^{\circ} \mathrm{C}\right)$ for periods of up to 42 days, there was a significant decrease ( 10 to $10^{4}$ fold) in the recovered viable count for all strains. Furthermore, all six B. cenocepacia strains survived for at least 199 dayswhich is 5 times the 40-day period - in the presence of 5$50 \mu \mathrm{g} / \mathrm{ml} \mathrm{CHX}$ and BZK. These results are consistent with our previous studies in which $B$. cenocepacia strains were intrinsically resistant to a wide range of antiseptics and were shown to survive for at least 28 days in the presence of CHX and BZK $[3,16,21]$.

USP $<62>$ tests allow the detection or limited occurrence of specified microorganisms that may be present under the conditions described [24]. The bacterial test strains were grown in culture vessels containing TSB or TSA at $30^{\circ} \mathrm{C}$ to $35^{\circ} \mathrm{C}$ for 18 to $24 \mathrm{~h}$. We compared the currently accepted TSA (or TSB) media methods in USP $<61>$ and USP $<62>$ to the diluted media methods for the detection of BCC $[20,23$, 24]. TSA (or TSB) media was developed for use as a general purpose medium, providing enough nutrients to allow for a wide variety of microorganisms to grow [23, 24]. The ability to grow and persist in multiple environments appears to be the key factor that promotes BCC persistence. Lag phase depends on the physiological state of the inoculum, as well as on growth conditions. Temperature-dependent and nutrient-depleted environments could alter the lag phase of growth. B. cenocepacia AU19236 had a significantly longer lag phase at $6^{\circ} \mathrm{C}(17.6-27.4 \mathrm{~h})$ than at $23^{\circ} \mathrm{C}$ and $42^{\circ} \mathrm{C}$ (10.1-14.2 h). However, no significant differences in lag times were observed between TSB and oligotrophic media.

R2A seemed the most appropriate medium to detect bacteria from water samples, and is recommended by the American Society for Testing and Materials (ASTM) for testing of water quality [41]. Our comparison of TSA/B and oligotrophic medium $(1 / 10 \times \mathrm{TSA} / \mathrm{B}, 1 / 3 \times \mathrm{R} 2 \mathrm{~A} / \mathrm{B}$, and $\mathrm{R} 2 \mathrm{~A} / \mathrm{B}$ ) demonstrated that samples recovered in oligotrophic medium resulted in significantly higher recovery rates of $\mathrm{BCC}$ in autoclaved distilled water and in antiseptics at $23^{\circ} \mathrm{C}, 6^{\circ} \mathrm{C}$ and $42^{\circ} \mathrm{C}$ storage for 42 days than recovered in TSA (Tables 2, 3, and 4). These findings are consistent with our previous studies evaluating the recovery of BCC from distilled water and antiseptic solution at $23^{\circ} \mathrm{C}$ $[16,20]$. This result is in agreement with findings that higher recovery frequencies and larger population densities of BCC have been reported from water, soil and crop rhizospheres using low-nutrient, nonselective media [20, 28-31, 42, 43]. Furthermore, Peeters et al. [43] reported that a higher number of distinct colony morphologies were present on the ten-fold diluted formulation of Pseudomonas cepacia azelaic acid tryptamine medium $(1 / 10 \times$ PCAT). It is possible that the nutrient-rich conventional growth media may favor the growth of faster-growing bacteria at the expense of slow-growing ones. This media may also inhibit or place metabolic stress on nutrient-limited water populations of BCC. Although TSA/B is generally considered the medium of choice, technical specifications for the USP survey of BCC in non-sterile pharmaceutical materials allow for different oligotrophic agar to be used.

USP <62> "Microbiological examination of non-sterile products: tests for specified microorganisms" is performed routinely to test for the presence of Staphylococcus aureus, Pseudomonas aeruginosa, Escherichia coli, bile-tolerant Gram-negative bacteria, Clostridia species, Salmonella species and/or Candida albicans [24]. A test sample is first enriched by inoculation into soybean casien digest broth (TSB), then streaking onto selective agars to determine the presence of specified microorganisms [24]. The pre-enrichment of samples is used as a means of increasing sensitivity and test reliability. In this study, by direct culture on TSA, BCC was not detected in water samples at $23^{\circ} \mathrm{C}$ (initial serial dilution $10^{-10}, 10^{-11}$, and $10^{-12}$ ). However, broth media used were about ten-fold to a hundred-fold more sensitive (one to two order of magnitude greater) than any solid medium tested (Tables 2 and 3). Previously, Vermis et al. [26] reported that liquid enrichment prior to plating may enhance the isolation of 
BCC from water samples, suggesting that liquid enrichment is necessary in support of BCC recovery. Moreover, we reported that the superiority of broth over solid media is also supported by recovery of $B$. cenocepacia from distilled water [20]. The kind of agar used as a solidifying agent may interfere in the early stages of growth. The growth of motile species such as $P$. aeruginosa, L. monocytogenes, $S$. typhimurium and E. coli is affected by agar concentration (reduced water activity); these species typically do not grow on media with elevated agar concentrations [44]. The need for a stress recovery phase to recover microorganisms was demonstrated by longer incubation times and consistently higher recovery on low-nutrient media and temperatures below $35^{\circ} \mathrm{C}$. The culture method and medium used influenced the recovery of some BCC samples from distilled water and antiseptic samples. Low nutrient media as a pre-enrichment step are strongly supported for the compendial test method for BCC detection.

The use of the Tukey's HSD test showed that oligotrophic solid media were observed to have higher BCC recovery rates compared with TSA. In addition, the number of bacteria recovered with different broth media indicated that oligotrophic broth media provide for the highest recovery of BCC. The differences between oligotrophic media and TSB or TSA medium for growth or survival in this study were due to the favorable nutritional composition of oligotrophics, compared to a high nutrition medium. On the basis of our experiments, R2A and dilutions of TSA constituted better enrichment media for the recovery of BCC from distilled water and antiseptics. In addition, the recovery of microorganisms from distilled water samples and antiseptics increased by using a pre-enrichment medium. Results in this study provide confirmatory data for USP in support of its proposed compendial chapter for BCC detection. Results from this study clearly demonstrate the utility of using diluted media and enriched cultures with a pre-enrichment step as a superior strategy in the compendial test method USP $<60>$ for BCC recovery and detection [45]. Furthermore, this study provides a comprehensive data set that supports the USP inclusion of lower nutrient, resuscitative media as suggested previously $[18,20]$.

\section{Acknowledgments}

The manuscript is dedicated to the late Mr. Walter Bond for his seminal research contributions on the recovery of Burkholderia cepacia from nebulizer fluids that stimulated the research presented in this paper as well as to the development of the USP chapter on this subject. The views presented in this article do not necessarily reflect those of the Food and Drug Administration.

\section{Conflict of Interest}

The authors have no financial conflicts of interest to declare.

\section{References}

1. DSMZ. 2019. Prokaryotic nomenclature up-to-date. Available from https://www.dsmz.de/bacterial-diversity/prokaryoticnomenclature-up-to-date/prokaryotic-nomenclature-up-to-date. html. Accessed May 17, 2019.

2. Peeters C, Zlosnik JEA, Spilker T, Hird TJ, LiPuma JJ, Vandamme P. 2013. Burkholderia pseudornultivorans sp nov., a novel Burkholderia cepacia complex species from human respiratory samples and the rhizosphere. Syst. Appl. Microbiol. 36: 483-489.

3. Ahn Y, Kim JM, Kweon O, Kim SJ, Jones RC, Woodling K, et al. 2016. Intrinsic resistance of Burkholderia cepacia complex to benzalkonium chloride. MBio. 7: e01716.

4. Martina P, Leguizamon M, Prieto CI, Sousa SA, Montanaro P, Draghi WO, et al. 2018. Burkholderia puraquae sp. nov., a novel species of the Burkholderia cepacia complex isolated from hospital settings and agricultural soils. Int. J. Syst. Evol. Microbiol. 68: 14-20.

5. Peeters C, Meier-Kolthoff JP, Verheyde B, De Brandt E, Cooper VS, Vandamme P. 2016. Phylogenomic study of Burkholderia glathei-like organisms, proposal of 13 novel Burkholderia species and emended descriptions of Burkholderia sordidicola, Burkholderia zhejiangensis, and Burkholderia grimmiae. Front Microbiol. 7: 877.

6. Mahenthiralingam E, Baldwin A, Dowson CG. 2008. Burkholderia cepacia complex bacteria: opportunistic pathogens with important natural biology. J. Appl. Microbiol. 104: 15391551.

7. FDA. 2017. FDA updates on 2017 Burkholderia cepacia contamination. Available from https://www.fda.gov/Drugs/ DrugSafety/ucm570672.htm. Accessed May 17, 2019.

8. FDA. 2017. FDA advises drug manufacturers that Burkholderia cepacia complex poses a contamination risk in non-sterile, water-based drug products. Available from https://www.fda.gov/Drugs/DrugSafety/ucm559508.htm. Accessed May 17, 2019.

9. CDC. 2017. Multistate outbreak of Burkholderia cepacia infections associated with oral liquid docusate sodium. Available from https://www.cdc.gov/hai/outbreaks/bcepacia/. Accessed May 17, 2019.

10. CDC. 2017. Multistate outbreak of Burkholderia cepacia bloodstream infections associated with contaminated prefilled 
saline flush syringes. Available from https://www.cdc.gov/ hai/outbreaks/b-cepacia-saline-flush/index.html. Accessed May 17, 2019.

11. CDC. 2018. Multistate outbreak of Burkholderia cepacia complex infections associated with the use of medline remedy essentials no-rinse cleaning foam. Available from https://www.cdc.gov/hai/outbreaks/b-cepacia/no-rinse.html. Accessed May 17, 2019.

12. Becker SL, Berger FK, Feldner SK, Karliova I, Haber M, Mellmann A, et al. 2018. Outbreak of Burkholderia cepacia complex infections associated with contaminated octenidine mouthwash solution, Germany, August to September 2018. Euro. Surveill. 23: 1800540.

13. Torbeck L RD, Guilfoyle DE, Friedman RL, Hussong D. 2011. Burkholderia cepacia: This decision is overdue. PDA J. Pharm. Sci. Technol. 65: 535-543.

14. Jimenez L. 2007. Microbial diversity in pharmaceutical product recalls and environments. PDA J. Pharm. Sci. Technol. 61: 383-399.

15. Robertson J, Levy A, Sagripanti JL, Inglis TJJ. 2010. The Survival of Burkholderia pseudomallei in Liquid Media. Am. J. Trop. Med. Hyg. 82: 88-94.

16. Kim JM, Ahn Y, LiPuma JJ, Hussong D, Cerniglia CE. 2015. Survival and susceptibility of Burkholderia cepacia complex in chlorhexidine gluconate and benzalkonium chloride. J. Ind. Microbiol. Biotechnol. 42: 905-913.

17. Gilligan PH, Whittier S. 1999. Burkholderia, Stenotrophomonas, Ralstonia, Brevundimonas, Comamonas, and Acidovorax, pp. 526538. In Murray PR, Baron EJ, Pfaller MA, Tenover FC, Yolken RH (eds.), Manual of clinical microbiology, $7^{\text {th }}$ ed. American Society for Microbiology, Washington, D.C.

18. Carson LA, Favero MS, Bond WW, Petersen NJ. 1973. Morphological, biochemical, and growth characteristics of Pseudomonas cepacia from distilled water. Appl. Microbiol. 25: 476-483.

19. Chiarini L, Bevivino A, Dalmastri C, Tabacchioni S, Visca P. 2006. Burkholderia cepacia complex species: health hazards and biotechnological potential. Trends Microbiol. 14: 277-286.

20. Ahn Y, Kim JM, Ahn H, Lee YJ, LiPuma J, Hussong D, et al. 2014. Evaluation of liquid and solid culture media for the recovery and enrichment of Burkholderia cenocepacia from distilled water J. Ind. Microbiol. Biotechnol. 41: 1109-1118.

21. Ahn Y, Kim JM, Lee YJ, LiPuma J, Hussong D, Marasa B, et al. 2017. Effects of extended storage of chlorhexidine gluconate and benzalkonium chloride solutions on the viability of Burkholderia cenocepacia. J. Microbiol. Biotechnol. 27: 2211-2220.

22. USP. 2016. <1111> Microbiological examination of non-sterile products: acceptance criteria for pharmaceutical preparations and substances for pharmaceutical use. Available from https://www.usp.org/sites/default/files/usp/document/ harmonization/gen-method/q05c_pf_ira_33_2_2007.pdf. Accessed May 17, 2019.
23. USP. 2016. <61> Microbiological examination of nonsterile products - microbial enumeration tests. Available from https://hmc.usp.org/sites/default/files/documents/HMC/ GCs-Pdfs/c61.pdf. Accessed May 17, 2019.

24. USP. 2016. $<62>$ Microbiological examination of nonsterile products - tests for specified microorganisms. Available from https://www.usp.org/sites/default/files/usp/document/ harmonization/gen-method/q05a_pf_ira_34_6_2008.pdf. Accessed May 17, 2019.

25. Vanlaere E, Coenye T, Samyn E, Van den Plas C, Govan J, De Baets F, et al. 2005. A novel strategy for the isolation and identification of environmental Burkholderia cepacia complex bacteria. FEMS Microbiol. Lett. 249: 303-307.

26. Vermis K, Brachkova M, Vandamme P, Nelis H. 2003. Isolation of Burkholderia cepacia complex genomovars from waters. Syst. Appl. Microbiol. 26: 595-600.

27. Carson LA, Tablan OC, Cusick LB, Jarvis WR, Favero MS, Bland LA. 1988. Comparative evaluation of selective media for isolation of Pseudomonas cepacia from cystic fibrosis patients and environmental sources. J. Clin. Microbiol. 26: 2096-2100.

28. Kawai M, Matsutera E, Kanda H, Yamaguchi N, Tani K, Nasu M. 2002. 16S ribosomal DNA-based analysis of bacterial diversity in purified water used in pharmaceutical manufacturing processes by PCR and denaturing gradient gel electrophoresis. Appl. Environ. Microbiol. 68: 699-704.

29. Nagarkar PP, Ravetkar SD, Watve MG. 2001. Oligophilic bacteria as tools to monitor aseptic pharmaceutical production units. Appl. Environ. Microbiol. 67: 1371-1374.

30. Venkateswaran K, Hattori N, La Duc MT, Kern R. 2003. ATP as a biomarker of viable microorganisms in clean-room facilities. J. Microbiol. Methods. 52: 367-377.

31. Kulakov LA, McAlister MB, Ogden KL, Larkin MJ, O'Hanlon JF. 2002. Analysis of bacteria contaminating ultrapure water in industrial systems. Appl. Environ. Microbiol. 68: 1548-1555.

32. Baranyi J, Roberts TA. 1994. A dynamic approach to predicting bacterial growth in food. Int. J. Food Microbiol. 23: 277-294.

33. Cassidy MB, Leung KT, Lee H, Trevors JT. 2000. A comparison of enumeration methods for culturable Pseudomonas fluorescens cells marked with green fluorescent protein. J. Microbiol. Methods 40: 135-145.

34. Jin M, Wang B. 2014. Implementing multiple comparisons on pearson chi-square test for an $\mathrm{R} \times \mathrm{C}$ contingency table in SAS. SAS Global Forum Proc. 1544: 1541-1546

35. Schaffter N, Parriaux A. 2002. Pathogenic-bacterial water contamination in mountainous catchments. Water Res. 36: 131-139.

36. Pumpuang A, Chantratita N, Wikraiphat C, Saiprom N, Day NPJ, Peacock SJ, et al. 2011. Survival of Burkholderia pseudomallei in distilled water for 16 years. Trans. $R$. Soc. Trop. Med. Hyg. 105: 598-600. 
37. Gilbert SE, Rose LJ. 2012. Survival and persistence of nonspore-forming biothreat agents in water. Lett. Appl. Microbiol. 55: 189-194.

38. Moore RA, Tuanyok A, Woods DE. 2008. Survival of Burkholderia pseudomallei in water. BMC Res. Notes 1: 11.

39. Moore JE, Nagano Y, Millar BC, McCalmont M, Elborn JS, Rendall J, et al. 2007. Environmental persistence of Pseudomonas aeruginosa and Burkholderia multivorans in sea water: preliminary evidence of a viable but non-culturable state. Br. J. Biomed. Sci. 64: 129-131.

40. Tong S, Yang S, Lu Z, He W. 1996. Laboratory investigation of ecological factors influencing the environmental presence of Burkholderia pseudomallei. Microbiol. Immunol. 40: 451-453.

41. ASTM. 2012. ASTM F1094 - 87, Standard test methods for microbiological monitoring of water used for processing electron and microelectronic devices by direct pressure tap sampling valve and by the presterilized plastic bag method. Available from www.astm.org. Accessed May 17, 2019.
42. Hagedorn C, Gould WD, Bardinelli TR, Gustavson DR. 1987. A selective medium for enumeration and recovery of Pseudomonas cepacia biotypes from soil. Appl. Environ. Microbiol. 53: 2265-2268.

43. Peeters C, Depoorter E, Praet J, Vandamme P. 2016. Extensive cultivation of soil and water samples yields various pathogens in patients with cystic fibrosis but not Burkholderia multivorans. J. Cyst. Fibros. 15: 769-775.

44. Mitchell AJ, Wimpenny JW. 1997. The effects of agar concentration on the growth and morphology of submerged colonies of motile and non-motile bacteria. J. Appl. Microbiol. 83: 76-84.

45. Pharmawebinars. 2019. New proposed general chapter USP $<60>$ Microbiological examination of nonsterile products tests for Burkholderia cepacia complex. Available from https:// www.pharmawebinars.com/usp-60-tests-for-burkholderiacepacia-complex. Accessed May 17, 2019. 